\title{
ODONTOLOGIA E PRECEPTORIA: UM OLHAR PARA A PRÁTICA PEDAGÓGICA DOS PRECEPTORES DE ESTÁGIO
}

\section{Dentistry and Preceptorship: a Look at the Pedagogical Practice of Internship Preceptors}

\author{
Emanuelle Tenório de Oliveira \\ Universidade Federal de Alagoas - UFAL - Maceió (AL) - Brasil
}

Maria Viviane Lisboa de Vasconcelos

Universidade Federal de Alagoas - UFAL - Maceió (AL) - Brasil

Renato Santos Rodarte

Universidade Federal de Alagoas - UFAL - Maceió (AL) - Brasil

Roberto Zonato Esteves

Universidade Estadual de Maringá - UEM - Maringá (PR) - Brasil

\section{RESUMO}

Objetivo: Conhecer a preceptoria em odontologia sob o ponto de vista dos profissionais/cirurgiões dentistas quanto a sua função e prática pedagógica. Métodos: Trata-se de uma pesquisa com abordagem qualitativa na modalidade estudo de caso, com a técnica da entrevista semiestruturada e observação participante com os 12 cirurgiões dentistas que atuavam como preceptores de estágio no serviço público. Os dados foram interpretados a luz da técnica de análise de conteúdo temática. Resultados: Os preceptores relataram que reconhecem os cenários de pratica como locais de contextualização dos conteúdos teóricos apreendidos na instituição formadora; se apercebem como colaboradores na formação profissional do estudante e também se sentem como aprendizes do processo. Identificaram como dificuldades neste contexto a sua falta de formação pedagógica para exercer a preceptoria e o distanciamento entre a academia e o serviço. O cirurgião dentista/preceptor tem dificuldade de perceber o papel docente na sua função de preceptor. Há falta de estímulo para a atuação como preceptor, no sentido de treinamento e incentivo financeiro. Conclusão: É visível a necessidade de estreitar os vínculos com a instituição de ensino, através de parcerias e comunicações efetivas, planejamento e orientação quanto ao andamento dos momentos de estágio de forma geral.

Descritores: Preceptoria; Educação Continuada; Estágio; Odontologia.

\begin{abstract}
Objective: Know the preceptory in dentistry from the point of view of dentist professionals / surgeons as to their function and pedagogical practice. Methods: It is a research with qualitative approach in the case study modality with the adoption of the techniques of semi-structured interview and participant observation with the 12 dentist surgeons who acted as trainee preceptors in the public service. The data were interpreted according to Bardin content analysis technique. Results: The preceptors reported that they recognize the practice scenarios as places of contextualization of the theoretical contents learned in the training institution; perceive themselves as collaborators in the professional training of the student and also feel as learners of the process. They identified as difficulties in this context as their lack of pedagogical training to exercise the preceptory and the distance between the academy and the service. The dentist surgeon / preceptor has difficulty perceiving the teaching role in his preceptor function. There is a lack of stimulus (training and financiall incentive) to act as a preceptor. Conclusion: Is evident the need to strengthen bonds with the educational institution through effective partnerships and communications, planning and orientation regarding the progress of internship periods in general.
\end{abstract}

Descriptors: Preceptorship; Continuing Education; Clinical Clerkship; Dentistry. 


\section{INTRODUÇÃO}

Os Cursos de Odontologia, no Brasil, vêm sofrendo modificações para se adequarem ao perfil recomendado pelas Diretrizes Curriculares Nacionais do Curso de Graduação em Odontologia ${ }^{(1)}$. Em diferentes compassos enfrentam desafios para garantir a formação desse profissional generalista e humanista, que atue no Sistema Único de Saúde.

Nesse contexto, uma destas mudanças foi a inserção dos estágios supervisionados e de preceptores nos serviços públicos, extrapolando os muros da Universidade. A preceptoria auxilia a formação profissional, funcionando como elo entre o aprendiz e a prática profissional desenvolvida em um serviço ${ }^{(2,3)}$.

Os preceptores são educadores e precisam estar aptos a ajudar, motivar, inspirar e influenciar os discentes no aprendizado de forma positiva, a partir das práticas diárias. Interligam os estagiários com a realidade, por meio da reflexão, do diálogo e da participação.

Para atender as normas preconizadas nas DCN (2002)(1), para os cursos de Odontologia no Brasil, o Plano Pedagógico do Curso de Odontologia, da Universidade Federal de Alagoas ${ }^{(4)}$, reestrutura seu currículo e coloca como um de seus objetivos a formação de um cirurgião-dentista voltado para um atendimento mais humanizado com visão crítica e reflexiva, para atuar em todos os níveis de atenção à saúde, com base no rigor técnico e científico, devendo aprender continuamente, tanto na teoria, quanto na prática da profissão.

Observa-se que a educação permanente dos profissionais se torna a prática capaz de levá-los às atualizações e experiências de outros profissionais ${ }^{(5,6)}$. Desta forma, os profissionais de saúde deverão aprender a aprender, ter responsabilidade e compromisso com a sua educação, além de cooperarem com o treinamento e/ou o estágio das futuras gerações de profissionais, para que haja benefício mútuo entre os futuros profissionais e os dos serviços.

O tema desta pesquisa é a preceptoria, enquanto uma forma pedagógica de integrar teoria e prática em um campo de estágio e exercida por profissionais de nível superior da área da saúde ${ }^{(3,7,8)}$. Desta forma, para responder ao questionamento como se organiza a formação pedagógica do preceptor de odontologia, este trabalho propôs conhecer a preceptoria em odontologia, sob o ponto de vista dos profissionais/cirurgiões dentistas, quanto a sua função e prática pedagógica.

\section{MÉTODOS}

Com base nos marcos conceituais de que preceptor é o sujeito formador e orientador que ensina, supervisiona e conduz o aprendiz na sua profissão, escolheu-se a abordagem metodológica demandada pelo objeto que foi o Estudo de Caso, do tipo intrínseco e educacional, com abordagem qualitativa.

O Estudo de Caso é um método qualitativo que pode responder a questionamentos sobre o fenômeno estudado e contribui para compreendermos melhor os fenômenos individuais, os processos organizacionais e políticos da sociedade $^{(9)}$.

Nesta pesquisa, o Estudo de Caso tem característica intrínseca, visto que o pesquisador tem interesse específico neste "caso", que é a prática pedagógica do preceptor e a característica educacional, pois o mesmo está preocupado com a ação educativa(10).

Os participantes dessa pesquisa, escolhidos de modo intencional, foram os 12 cirurgiões dentistas que exerciam preceptoria, para os estudantes do $10^{\circ}$ período, do curso de Odontologia da Universidade Federal de Alagoas, no estágio supervisionado denominado de "extramuros" e que assinaram o termo de consentimento (TCLE).

Estes profissionais cirurgiões dentistas atuavam nas Unidades de Saúde de vários municípios: Messias, Marechal Deodoro e Barra de São Miguel, situados no Estado de Alagoas, nordeste do Brasil. A escolha deste cenário deveu-se à participação e vinculação dos três municípios com a atividade de Preceptoria junto aos estudantes do estágio curricular "extramuros", do curso de Odontologia.

Os procedimentos adotados para a construção dos dados foram dois: i) entrevista semiestruturada, individual, junto aos participantes, em seu local de trabalho, seguindo um roteiro pré-elaborado e pré-testado com perguntas norteadoras, com base nos objetivos da pesquisa e; ii) observação em campo, técnica que utiliza os sentidos na obtenção de determinados aspectos da realidade, que usualmente se complementa com outras técnicas como a entrevista semiestruturada e a análise documental, para tanto necessitando de ter critérios selecionados previamente.

A coleta dos dados ocorreu de abril a julho de 2015, sendo nove das 12 entrevistas realizadas nas Unidades de Saúde onde exerciam a preceptoria e três, por questões logísticas, efetuadas em outros locais previamente agendados. Segundo o cronograma dos estágios, comprovado pelos preceptores, os estudantes frequentavam os postos de saúde, duas a três vezes por semana. 
A primeira etapa da entrevista visou a caracterização deste profissional/cirurgião dentista, preceptor quanto a idade, sexo, atuação docente e capacitação para preceptoria. Na segunda etapa, foram efetuados questionamentos sobre a atuação pedagógica.

As entrevistas foram gravadas em áudio e registros manuais feitos pelo observador em um diário de campo. Durante o período da entrevista, foi possível observar os preceptores em seu ambiente natural de trabalho e sua maneira de conduzir o trabalho.

Todas as entrevistas gravadas em áudio foram transcritas integralmente e codificadas logo após o evento. Os Cirurgiões-Dentistas que participaram da pesquisa foram identificados pelas pela letra "P" (preceptor), seguidas de um número indicando a ordem cronológica das entrevistas, sequencialmente de "P1" a "P12", preservando o anonimato dos mesmos.

Durante o período da pesquisa, o pesquisador fez 20 entradas no campo, onde registrava suas impressões em um diário. As perguntas norteadoras da entrevista semiestruturada serviram como base à observação dos preceptores em seu ambiente de trabalho.

Para realização da análise do material verbal, optou-se pela Análise de Conteúdo temática ${ }^{(11)}$, técnica refinada cuja interpretação e contextualização dos dados vão gerar categorias estabelecidas pelos pesquisadores, a partir do conteúdo das entrevistas - categorias emergentes.

Esta pesquisa foi aprovada pelo Comitê de Ética em Pesquisa (CEP) da Universidade Federal de Alagoas (UFAL), pelo Parecer no 1.026.822, em 16 de abril de 2014 e os TCLE assinados por todos os participantes.

\section{RESULTADOS E DISCUSSÃO}

Todos os 12 preceptores cirurgiões dentistas concordaram em participar da pesquisa e foram caracterizados com uma média de idade de 35 anos, sendo 6 homens e 6 mulheres. Desses preceptores, cinco são docentes na Graduação, em cursos de especialização e em atualização na área de odontologia. No entanto, nenhum recebeu treinamento para preceptoria.

Os resultados foram embasados e discutidos a partir das falas dos entrevistados e, por meio de Análise de Conteúdo, emergiram as categorias associadas à preceptoria na Odontologia: "Prática Pedagógica", "Atuação do Preceptor" e "Cirurgião Dentista como Preceptor".

\section{Prática Pedagógica}

Em toda a área da saúde encontram-se discussões sobre a formação pedagógica dos profissionais e de como essa formação, ou mesmo a ausência dela, pode influenciar no ser docente assumido por esses profissionais, ao atuarem na função de supervisores, de tutores ou de preceptores dentro dos serviços de saúde ${ }^{(12)}$.

A prática pedagógica vem sendo objeto de estudo de vários autores e tem-se tornado um tema relevante na atualidade, devido a sua importância no êxito das práticas de ensino. Segundo Veiga ${ }^{(13)}$, essa prática deverá ter objetivos, finalidades, conhecimentos e estar dentro do contexto da prática social. Tozetto e de Sá ${ }^{(14)}$ defendem a necessidade de mobilizar os saberes, entre eles o do discurso abstrato para se preparar para a prática pedagógica e que, ao se direcionar essa prática para a ação de ensinar, adquire-se o saber da prática, a competência de ensinar.

Esta prática não é adquirida por repetição de ações do docente, mas desenvolve-se com consciência, sem dificuldades para a realizar e com a partilhar. A prática pedagógica deve estar ligada a um referencial teórico e metodológico.

No caso dos preceptores da Odontologia, a prática pedagógica se confunde com a prática clínica, sendo colocado pelos mesmos, muitas vezes, como sendo equivalentes.

"É mostrar no paciente o que é feito na odontologia, é a parte prática da coisa." (P2)

"A capacidade da pessoa de passar pra eles, de uma forma didática, de como eles podem desenvolver o trabalho." (P4).

"São os meios que você utiliza, né? Durante a rotina, no caso a Odontologia, aquela forma de abordagem de repente do paciente para tentar aproximar o conhecimento do aluno pra desenvolver a atividade como profissional no estágio." (P5).

“...a prática seria a explicação, passo a passo, do que eu estou fazendo." (P6)

“...é esse compartilhamento de conhecimento. O que eu faço de uma maneira mais empírica é compartilhar 
com eles o dia a dia mais prático da profissão." (P8)

“...a minha prática pedagógica seria minha prática diária.” (P10)

O movimento contemporâneo para uma formação mais generalista do profissional, como explicitado nas $\mathrm{DCN}^{(1)}$, ainda não está claro para os preceptores. Percebe-se ainda uma certa confusão sobre o significado do que é prática pedagógica, corroborada por expressões de ceticismo dos preceptores, durante as entrevistas. A ansiedade neste momento foi perceptível, demonstrando uma necessidade de aprovação ao que era respondido.

$O$ relato do preceptor $P 8$ descreve sua atuação com os estudantes:

"Eu acho que é mais por tentativa e erro... não sei se nos outros municípios é do mesmo jeito, mas o que é feito é cada um do seu jeito. Então se tivesse um nivelamento, saber como lidar com esse estudante, talvez fosse mais fácil". (P8)

Por outro lado, outros preceptores já mostram uma mudança de pensamento, ainda que sutil, no sentido de um treinamento mais adequado às exigências das $\mathrm{DCN}{ }^{(1)}$.

“...um apanhado de técnicas pedagógicas que o preceptor deveria executar, durante o estágio ou pós-graduação do estudante." (P3)

“...a capacidade da pessoa de passar pra eles, de uma forma didática, de como eles podem desenvolver o trabalho." (P4).

Fortes et al. ${ }^{(15)}$ referem que os processos de ensino-aprendizagem que ocorrem nos serviços apresentam elementos diferentes daqueles que ocorrem nas disciplinas básicas ou clínicas da odontologia.

“...e que esse aluno possa enxergar naquela prática pedagógica do seu preceptor o que ele vê em livro, em sala de aula." (P1)

Educar, para o docente e/ou preceptor, ultrapassa ensinar conteúdos específicos. Exige reflexão crítica. Segundo Freire ${ }^{(16)}$ seria impossível vir a tornar-se a pessoa em docente crítico, se for apenas um transmissor de informações. Essa reflexão de Freire nos remete ao tipo de preceptoria que se desenvolve, quando os preceptores apenas reproduzem suas práticas, sem darem espaços para momentos de reflexão.

Um estudo desenvolvido com preceptores de enfermagem mostra que a prática reflexiva leva a uma melhor compreensão da experiência, aumentando inclusive o vínculo da relação com o preceptor ${ }^{(17)}$.

Alguns cirurgiões dentistas/preceptores já pensam na importância de um acompanhamento mais didático e voltado à formação. Tanto que, ao longo da entrevista, se mostraram genuinamente interessados e preocupados em buscar alternativas para melhorarem os momentos de preceptoria:

"Eu acho que deveria ter cursos de qualificação, de médio a longo prazo realmente, como se fosse uma pósgraduação... Ter pelo menos um breve conhecimento do que é ter uma capacidade de uma prática pedagógica mais adequada." (P1)

"A capacitação seria ótima, até para saber o real interesse desse estágio, eu diria que sim, que seria interessante uma capacitação. Se tivesse a oferta, eu iria." (P4)

O papel do professor, ainda segundo Freire ${ }^{(16)}$ é a criação de possibilidades para a produção ou a construção do conhecimento. Assim, o cirurgião dentista/preceptor precisa oportunizar espaços e momentos para que o discente tenha suas próprias experiências, que busque as respostas sobre determinados assuntos.

O preceptor não pode se resumir a repassar sua prática clínica, como foi colocado pela maioria dos entrevistados. Para essa mudança, deve investir em sua formação pedagógica, para se manter atualizado e poder proporcionar um espaço de aprendizagem para ambos. Esse deve ser um processo conjunto entre a academia e o serviço, a formação e o desenvolvimento deste profissional para preceptoria.

No ensino superior, observa-se que a docência tem sido exercida por profissionais em que a grande maioria nunca teve contato com estudo de didática pedagógica. Além dessa limitação, as instituições de ensino superior têm privilegiado a experiência profissional do docente na sua área de formação e pouco em sua da capacitação pedagógica ${ }^{(18)}$.

Quando se fala em prática pedagógica, refere-se ao aprendizado que se constrói gradativamente por meio de várias experiências ${ }^{(19)}$. A discussão de temas, os valores adquiridos, a troca de vivências, os erros e os acertos, 
todos esses aspectos implicam num crescimento e desenvolvimento do sujeito enquanto profissional. Alguns dos entrevistados já demonstram em suas falas essa preocupação, de se criar um espaço de troca, de interação, mesmo colocando que são ainda práticas empíricas e pontuais.

“...é mais aquela coisa empírica, não é nada assim cientifico; é aquela rotina de ser aberto a discussões, de deixar os alunos à vontade para poderem interagir com o profissional... é aquela coisa mais de cotidiano." (P5)

O preceptor do curso de Odontologia, que se coloca como aquele que ensina a partir de sua prática profissional, como foi dito, sem ter tido a formação pedagógica para essa ação, atua na função de docente, sem ter tido contato prévio sobre os saberes didáticos e pedagógicos. De acordo com Rocha e Ribeiro(7), na grande maioria dos casos, os preceptores dominam os saberes e práticas profissionais, mas não são familiarizados com os saberes pedagógicos, levando a uma atuação intuitiva e de reprodutibilidade de modelos.

É importante que se compreenda que, apesar de existir uma prática pedagógica preconizada e ideal, este não é o único fator que influencia no bom andamento da preceptoria. Nesse sentido, observamos que muitos preceptores, mesmo sem terem tido contato formal com as práticas pedagógicas, conseguiram desenvolver de forma satisfatória a atividade de preceptoria, mesmo sendo de forma empírica e baseada fortemente em suas formações tecnicistas e nas suas disponibilidades e disposições para tal atuação.

\section{Atuação do Preceptor}

No que se refere ao desempenho da função docente através da preceptoria, os preceptores mencionaram o seguinte:

"São parecidas com a do docente. Preceptor e docente de sala não têm diferença; a diferença só é o ambiente de ensino." (P1)

"É orientar o aluno quanto a sua atividade profissional. Na verdade é uma docência, sendo na prática." (P6)

"Tem que ensinar, passar algum conhecimento. A gente tem que deixar que os acadêmicos fiquem à vontade pra poder desenvolver." (P7)

Esses depoimentos nos remetem à essência do preceptor de estágio, ou seja, à atitude de um educador na prática diária, levando o conhecimento através da reflexão, diálogo e participação, como afirmou Trajman et al.(2). Leva-nos a refletir se: i) ser preceptor equivale a ser docente, operando na prática, ou ii) ser preceptor é uma atividade com particularidades que não são pertinentes ou equivalentes a ser docente.

Os próprios cirurgiões-dentistas expressaram essa ideia, de se ter a necessidade de atuar como "docente" na prática clínica diária, ao mesmo tempo que demonstravam suas inseguranças. Questionavam-se se realmente essa seria a função deles, e sendo assim, até onde ela iria.

A atuação como "docente-clínico" não é exclusividade da área odontológica. Bentes et al. ${ }^{(20)}$ já discutiam que o papel de preceptor não seria uma opção pessoal dos profissionais médicos, mas uma condição assumida pelo fato de médicos estarem vinculados em uma instituição pública de saúde.

Santos et al..$^{\left({ }^{8}\right)}$ definem o preceptor como um "docente-clínico", com habilidades pedagógicas e clínicas, com intuito de dominar as habilidades técnicas e relacionais.

É importante ressaltar que, apesar de existir uma prática pedagógica preconizada, este não é o único fator que influencia o bom andamento da preceptoria. Como foi pelos autores observado, muitos preceptores, mesmo sem o contato formal com as práticas pedagógicas, conseguiram desenvolver satisfatoriamente a atividade de preceptoria, ainda que de forma empírica, baseada em sua formação tecnicista, na sua disponibilidade e na sua disposição para tal atuação.

Essa necessidade emergente de atuar como um "docente-clínico" não é exclusividade da área odontológica. Bentes et al. ${ }^{(2)}$ já discutiam que o papel de preceptor não seria uma opção pessoal dos profissionais médicos, mas uma condição assumida pelo fato de estar vinculado em uma instituição pública de saúde.

Sobre as funções exercidas durante a preceptoria, os preceptores mencionaram ser uma orientação prática, vincular teoria e prática, orientar, recepcionar, explicar, preparar o discente para a prática diária, ser um auxílio, um elo, ser capaz de agregar conhecimentos.

"Nossa função é fazer esse elo entre o paciente e o estagiário e o conhecimento." (P2) 
"Vincular o que eles aprendem na faculdade com a prática e tentar ensinar a eles na prática." (P1)

"São orientar, ensinar, explicar, tudo direitinho e colocar o estudante aqui pra trabalhar na prática." (P10)

É importante frisar que ao responder sobre as funções dos preceptores, mesmo existindo receios, os preceptores demonstraram clareza em suas opiniões, refletindo um conhecimento ainda que empírico sobre suas funções na preceptoria.

As funções de preceptor de estágio, como afirmam Botti e Rego ${ }^{(21)}$ ainda se confundem com as funções de mentores, tutores e docentes, mas a principal função do preceptor deve ser ensinar, refletir e trocar conhecimentos através de sua prática diária. Missaka e Ribeiro(22) colocam como características significativas o compromisso com a aprendizagem do aluno e o seu autoconhecimento sobre o papel de formador e incentivador.

A maioria dos entrevistados concorda que o espaço de preceptoria deve ser um ambiente para trocas de conhecimentos e reflexões sobre a prática. Em contrapartida, ao questioná-los sobre "o momento da preceptoria" afirmam que o trabalho poderia ser melhor desenvolvido e que está aquém da necessidade dos discentes.

"Recepcionar, mostrar como é que funciona a unidade... tem que ensinar, passar algum conhecimento. A gente tem que deixar que os acadêmicos fiquem à vontade pra poder desenvolver. " (P7)

“...que eu tento dar o meu melhor... eu não me sinto tão confortável." (P5)

"Não é completo, mas a gente tenta dar o que pode dar." (P2)

No depoimento do preceptor 5 e nas observações do momento da entrevista, nota-se que alguns preceptores estão dispostos a se comprometer mais com a atividade de formação. Há uma busca pela melhora na realização da preceptoria, embora não se sintam seguros e confortáveis, pela questão da formação, da responsabilidade, dos limites e da organização do estágio.

Pode-se observar ainda muitas dúvidas e receios entre os preceptores sobre os limites de suas atividades enquanto preceptores, quais sejam seus reais deveres com os seus discentes e até que ponto eles podem interferir na formação dos discentes.

Segundo Missaka ${ }^{(22)}$, a relação entre preceptor e aluno é uma relação de troca, de aprendizagem; é pedagógica, devendo cumprir os preceitos de toda relação pedagógica como ética, compromisso, potencialização da aprendizagem e melhoria da predisposição para ouvir.

Ao exercer a atividade de preceptoria, o profissional do serviço de saúde sente-se muitas vezes desnorteado, ao deparar-se com uma demanda para a qual não foi preparado. O preceptor do curso de Odontologia encontra um ambiente institucional que lhe cobra uma atuação profissional, uma atuação docente para responder a necessidade do próprio sistema de saúde e uma necessidade de formação dos discentes. Forma-se então um novo cenário de atuação em que os novos desafios para sua prática aumentam a cada dia, exigindo do preceptor atualização e compromisso( ${ }^{(7,8,23)}$.

Ao serem questionados sobre o ser preceptor, dentro do contexto das entrevistas, os profissionais de Odontologia muitas vezes citavam o ser docente com equivalente a ser preceptor. $E$ apesar de não conseguirem se enxergar como docentes, eles reconheciam que a preceptoria seria uma atividade docente inata.

"Eu poderia melhorar mais, eu preciso me melhorar como preceptora, a responsabilidade é grande." (P1)

Neste sentido, observa-se que os participantes da pesquisa conhecem e compreendem o que é ser preceptor na teoria, embora tenham dúvidas e receios quanto a sua aplicação prática e até sentem-se inseguros e despreparados para tal atividade.

\section{Cirurgião-dentista como Preceptor}

Dentre os 12 preceptores, cinco atuam como docentes e três desses mencionam alguma formação pedagógica adquirida, em programa de mestrado e em curso de formação de tutores. Todavia, todos aludem falta de capacitação pela instituição para a atuação na preceptoria.

Toda atividade de ensino, seja dentro da academia, seja desenvolvida através das preceptorias do serviço, exige comprometimento e responsabilidade. De acordo com Freire ${ }^{(16)}$, ensinar exige reflexão crítica sobre a prática, na formação permanente dos professores, dito que o momento fundamental seja esse. É pensando criticamente a prática que se pode melhorar e avançar. 
Algumas falas dos preceptores da Odontologia refletem uma prática de preceptoria ainda muito intuitiva e reprodutiva, ou seja, muito seguidora dos modelos de ensino que aprenderam, assim como acontece nas preceptorias de outros cursos da área da Saúde ${ }^{(22,24)}$ :

"Eu era instrutora de nível médio dos THD (técnicos de higiene dental) e ACD (auxiliar de consultório dental), do curso do Estado de Odontologia. Eu tive um treinamento sobre prática pedagógica... Pra ser preceptora dos alunos da Odonto não. No dia a dia, não tive nenhum curso." (P1)

"Não me recordo de nada voltado para a docência... pedagogicamente talvez não. Mas eu me considero capacitado do ponto de vista de ter boa intenção, de ter a boa vontade, de ter disponibilidade, mas a parte pedagógica eu não sei nem avaliar." (P3)

"Pedagogicamente não, porque eu não tenho noção justamente do que eu vou e como orientar." (P6)

"Na relação preceptor com aluno, talvez a gente precisasse fazer um curso. Eu acho que precisaria de uma formação, de uma capacitação dos profissionais que vão receber os estagiários e uma conscientização por parte da coordenação pra valorizar a importância deles estarem vindo pra cá." (P7)

“... eu não tenho nenhuma formação dessa parte de docência." (P8)

"Formação sobre prática pedagógica da preceptoria nunca tive nenhuma formação específica, mas eu tive a formação da parte pedagógica educacional no mestrado." (P9)

Alguns demonstram insatisfação e despreparo para exercer tal atividade:

"Na verdade como eu não fui orientada, eu faço o meu trabalho." (P6)

“...um trabalho injusto pra mim como preceptor, porque eu não consigo passar para o estagiário." (P9)

"Eu não tenho nenhum curso, nenhuma formação... Há dez anos recebo os estagiários e nunca tive nenhuma formação, nada." (P10)

Não só verbalizando, mas em suas expressões corporais os entrevistados demonstraram sua insatisfação com a falta de treinamento prévio ao estágio, deixando explícito o interesse em participarem de momentos de treinamento. Outros mostraram-se insatisfeitos e contrariados por estarem atuando como preceptores: P6 mostrou-se desinteressado em receber os discentes e desconfortável por se sentir obrigado a essa função; P9 mostrou-se insatisfeito porque, segundo ele, a falta de treinamento prévio impedia o desenvolvimento de um bom estágio.

As $\mathrm{DCN}^{(1)}$ e o PPC ${ }^{(4)}$ sugerem que, no exercício da preceptoria em Odontologia, ocorra comprometimento dos profissionais envolvidos e criação de momentos de formação e capacitação para desenvolverem as atividades de forma segura e com competência. Pensa-se que tal prática deva permita auxiliar os discentes no aprendizado, na prática do estágio "extramuros". Freire ${ }^{(16)}$ afirmava que toda atividade de ensino exige competência profissional, segurança, generosidade e comprometimento por parte dos profissionais envolvidos com sua própria formação.

Apesar de cinco entrevistados atuarem como docentes, todos relataram que usam a sua experiência profissional para embasar sua atuação na preceptoria. Quando os entrevistados se dizem preparados à preceptoria, eles acabam correlacionando com sua experiência clínica:

"Eu me sinto preparado por conta da experiência que eu já tenho, mas por formação pra isso - preceptoria não." (P1)

"Eu me considero capacitado do ponto de vista de ter boa intenção, de ter a boa vontade, de ter disponibilidade, mas a parte pedagógica eu não sei nem avaliar." (P3)

"Eu uso um pouco da parte científica que eu passo pra eles, mas pedagógica não, até porque eu não tenho essa orientação." (P6)

"Nunca recebi nada de formação... está faltando um pouquinho mais de capacitação, de dedicação." (P12)

Ao justificarem suas falas sobre se sentirem capacitados para a preceptoria, a grande maioria refere sua experiência clínica, mas em nenhum momento eles expuseram que se sentiam confortáveis em receber os discentes, por terem recebido um treinamento pedagógico específico para preceptoria.

De acordo com a Portaria Interministerial $n^{\circ} 1.124$, de 4 de agosto de $2015^{(25)}$, compete às IES oferecer aos profissionais da rede de serviços oportunidades de formação e desenvolvimento que contribuam com a qualificação da assistência, da gestão, do ensino e do controle social na saúde, com base na Política Nacional de Educação 
Permanente em Saúde. Além de fomentar ações de valorização e formação voltadas para os preceptores, tais como inclusão em pesquisas (como pesquisadores), como certificação da atividade de preceptoria, como apoio à participação em atividades como cursos, congressos, dentre outros modos de formação, esses apoios deverão estar explicitados nos Contratos Organizativos de Ação Pública Ensino Saúde (COAPES).

Outros preceptores demonstram maior segurança por entenderem que a sua formação cientifica era suficiente para prepará-los para a preceptoria.

"Particularmente eu me acho, porque com tantas pós-graduações sempre foi passado um pouquinho do que é uma prática pedagógica pra os alunos. Eu me sinto preparado por conta da experiência." (P1)

"Eu tenho, assim pelo meu conhecimento, eu posso passar o que eu sei, meu conhecimento científico ou prático mesmo. É como às vezes eu digo a eles." (P6)

Nesse contexto, portanto, é preciso refletir sobre a forma como a educação permanente em Saúde vem atuando, como os polos de Educação permanente e os programas como o Pró-saúde vêm incentivando e articulando as mudanças nas formas de ensino, na área da Saúde e reorientando os profissionais para se adequarem às sugestões das Diretrizes Curriculares Nacionais dos Cursos de Graduação em Odontologia( ${ }^{(1)}$.

\section{CONSIDERAÇÕES FINAIS}

A prática pedagógica desenvolvida pelos preceptores ainda é incipiente e descontextualizada, embora já se observe alguma mudança de pensamento e postura em relação à preceptoria. Os preceptores têm essa percepção e demonstram preocupação com a formação do discente e sentem necessidade de treinamento específico para a preceptoria.

Os cirurgiões-dentistas, enquanto preceptores, acabam reproduzindo no exercício da preceptoria uma formação sem espaço para reflexões ou para grandes trocas de conhecimento, superestimando apenas o "passo a passo clínico".

Apesar das $\mathrm{DCN}^{(1)}$ colocarem como prioridade a formação do Odontólogo, voltado para o Sistema Único de Saúde (SUS), e sugerirem o perfil do profissional, que deve cooperar com o treinamento e estágio das futuras gerações, ainda é desconhecido por alguns preceptores que todo profissional que ingressa no serviço público tem o dever de auxiliar na formação destes discentes. Todavia, em alguns casos, resulta em prejuízos ao andamento dos estágios.

Dificuldades em perceber o ser docente na sua função de preceptor, falta de estímulo e de perfil para a atuação nesta função são alguns dos desafios a serem vencidos, para que os profissionais da Odontologia consigam realizar a preceptoria em serviço. Além dessas constatações, há a necessidade de vencer seus receios e inseguranças para desenvolverem a preceptoria de forma mais tranquila.

Há uma fragilidade do estágio "extramuros" e na sua organização. A ausência de um mecanismo de institucionalização entre a IES e o Serviço gera um conflito de deveres, de direitos e de limites, no planejamento do estágio. Por essas circunstâncias, justifica-se a necessidade de estreitar os vínculos com a instituição, através de parcerias e comunicações efetivas, planejamento e orientação quanto ao andamento dos momentos de estágio, de forma geral.

Para buscar uma transformação nesse cenário e melhoria no desenvolvimento da preceptoria, sugerimos uma formação permanente do profissional do serviço para atuação como preceptor; um planejamento conjunto das ações com os serviços e instituição de ensino, sensibilizando os preceptores para fazerem parte integrante desse processo; uma criação de momentos de formação e reflexão das práticas de preceptoria, visando a partilha de experiências, receios, medos e fortalecimento do vínculo formal entre a IES e as unidades de saúde envolvidas, através da participação dos preceptores em todo o processo.

\section{CONFLITOS DE INTERESSE}

Os autores afirmam que não há conflitos de interesse.

Artigo baseado na Dissertação: "Odontologia e preceptoria: um olhar para a prática pedagógica dos preceptores de estágio" - Faculdade de Medicina - UFAL. Defesa: dezembro, 2016. 120 p.

\section{REFERÊNCIAS}

1. Brasil, Ministério da Educação. Conselho Nacional de Educação/Câmara de Educação Superior. Resolução CNE/CES 3, de 19 de fevereiro de 2002. Institui Diretrizes Curriculares Nacionais do Curso de Graduação em 
Odontologia. Diário Oficial União. 04 mar 2002; Seção1:10. Disponível em: URL: http://portal.mec.gov.br/cne/ arquivos/pdf/CES032002.pdf

2. Trajman $A$, Assunção N, Venturi M, Tobias D; Toschi W, Brant V. A preceptoria na rede básica da Secretaria Municipal de Saúde do Rio de Janeiro: opinião dos profissionais de Saúde. Revista Brasileira de Educação Médica. Rio de Janeiro, v. 33, n. 1, Mar. 2009. Disponível em: URL: http://www.scielo.br/scielo.php?script=sci arttext\&pid=S0100-55022009000100004\&Ing=en\&nrm=iso. Acessado em 20 set. 2014. DOI: http://dx.doi. org/10.1590/S0100-55022009000100004

3. Botti SHO, Rego STA. Docente-clínico: o complexo papel do preceptor na residência médica. Physis, Rio de Janeiro, v. 21, n. 1, p. 65-85, 2011. Disponível em: URL: http://www.scielo.br/scielo.php?script=sci_arttext\&pid=S010373312011000100005\&lng=en\&nrm=iso. Acessado em 20 de agosto 2014. DOI: http://dx.doi.org/10.1590/S010373312011000100005

4. Projeto Político Pedagógico do curso de Odontologia da Universidade Federal de Alagoas. UFAL, Maceió, 2007.

5. Ceccim, RB. Educação Permanente em Saúde: descentralização e disseminação de capacidade pedagógica na saúde. Ciências Saúde Coletiva, Rio de Janeiro, v. 10, n. 4, p.975-986, Dez. 2005. Disponível em: URL: http:// www.scielo.br/scielo.php?script=sci_arttext\&pid=S1413-81232005000400020\&lng=en\&nrm=iso. Acessado em 15 Jul. 2014. DOI: http://dx.doi.org/10.1590/S1413-81232005000400020

6. Sarreta FO. Educação permanente em saúde para os trabalhadores do SUS. São Paulo: Cultura Acadêmica da Fundação UNESP, v.1.252f. 2010.

7. Rocha HC, Ribeiro VB. Curso de formação pedagógica para preceptores do internato médico. Revista Brasileira de Educação Médica, Rio de Janeiro, v. 36, n. 03, set. 2012. Disponível em: URL: http://educa.fcc.org.br/scielo. php?script=sci_arttext\&pid=S1981-52712012000500008\&lng=es\&nrm=iso. Acessado em 05 de outubro de 2014.

8. Santos AC, Lima AA, Lima BLG, Silva CDA, Viggiano DPPO, Carvalho GS, et al. Competências da Preceptoria na Residência Médica. Cadernos da ABEM. Rio de Janeiro: Associação Brasileira de Educação Médica Vol. 9. p.40-45. Out. 2013.

9. Yin RK. Estudo de Caso - Planejamento e Método. $2^{\mathrm{a}}$ ed. São Paulo: Bookman, 2001.

10. André MED. A. Estudo de Caso em Pesquisa e avaliação educacional. Brasília: Liber Livro Editora, 2005.

11. Bardin L. Análise de Conteúdo. Tradução de Luís Antero Reto e Augusto Pinheiro. $3^{\mathrm{a}}$ ed. Lisboa/Portugal: Edições 70, 2011.

12. Cerqueira, P. A formação pedagógica de preceptores dos estudantes da área da saúde: ma conversa em três tempos. In: Brant V (Org). Formação Pedagógica de Preceptores do Ensino em Saúde. Juiz de Fora: Ed. UFJF, p. 67-75, 2011.

13. Veiga IPA. A prática pedagógica do professor de Didática. $2^{\mathrm{a}}$ ed. Campinas: Papirus, 1992.

14. Tozetto SS, de Sá GT. A prática pedagógica na formação docente. Reflexão e Ação, v. 17, n. 2, p. 181-196, 2009.

15. Fortes, FDS, Pessoa, TRFF, Freitas, CHSM, Pereira, CAL, Carvalho Junior, PM. Reorientação na formação de cirurgiões-dentistas: o olhar dos preceptores sobre estágios supervisionados no Sistema Único de Saúde (SUS). Interface (Botucatu), 2015; 19 Supl. 1:831-43.

16. Freire P. Pedagogia da Autonomia: saberes necessários à prática educativa. $25^{a}$ ed. São Paulo: Paz e Terra, 1996.

17. Duffy A. Guiding students through reflective practice - the preceptors' experiences. A qualitative descriptive study. Nurse Educ Pract. 2009; 9 (3): 166-75.

18. Barreto VHL, Monteiro ROS, Magalhães GSG, Almeida RCC, Souza LN. Papel do preceptor da atenção primária em saúde na formação da graduação e pós-graduação da Universidade Federal de Pernambuco: um termo de referência. Revista Brasileira de Educação Médica, Rio de Janeiro, v. 35, n. 04, dic. 2011. Disponível em: URL: http://educa.fcc.org.br/scielo.php?script=sci_arttext\&pid=S1981-52712011000400019\&lng=es\&nrm=iso. Acessado em maio de 2014.

19. Silva AS, Moreira SMS. Os saberes docentes para a prática pedagógica de alunos com necessidades educativas 
especiais na escola regular. 2014. Dissertação (Mestrado em Educação). Universidade Estadual de Feira de Santana, 2014.

20. Bentes A, Leite AJM, Montenegro APDR, Paiva Júnior BR, Fernandes CR, Chiesa D, et al. Preceptor de Residência Médica: Funções, Competências e Desafios. A Contribuição de quem valoriza porque percebe a Importância: Nós Mesmos!. Cadernos da ABEM. Rio de Janeiro: Associação Brasileira de Educação Médica Vol. 9. p.32-38. Out. 2013.

21. Botti SHO, Rego S. Preceptor, supervisor, tutor e mentor: quais são seus papéis? Revista Brasileira de Educação Médica, Rio de Janeiro, v. 32, n. 3, Set. 2008. Disponível em: URL: http://www.scielo.br/scielo.php?script=sci_ arttext\&pid=S0100-55022008000300011\&lng=en\&nrm=iso. Acesso em 20 Jun 2014. DOI: http://dx.doi.org/10.1590/ S0100-55022008000300011

22. Missaka H. A Prática Pedagógica dos Preceptores do Internato em Emergência e Medicina Intensiva de um Serviço Público Não Universitário. Dissertação (Mestrado), 2010. 66f. Universidade Federal do Rio de Janeiro, RJ, 2010.

23. Missaka $H$, Ribeiro VMB. A preceptoria na formação médica: o que dizem os trabalhos nos congressos Brasileiros de educação médica 2007-2009. Revista Brasileira de Educação Médica, Rio de Janeiro, v. 35, n. 3, Set. 2011.

24. Maria VOS, Silva MVG, Berardinelli LMM. Preceptoria: elo da integração docente assistencial - suporte para o internato de enfermagem. Revista Brasileira de Enfermagem, Brasília, v. 44, n. 1, p. 49-54, Mar., 1991. Disponível em: URL: http://www.scielo.br/scielo.php?script=sci_arttext\&pid=S0034-71671991000100009\&lng=en\&nrm=i so>. Acessado em 15 de março de 2016. DOI: http://dx.doi.org/10.1590/S0034-71671991000100009

25. Brasil, Ministério da Saúde e Ministério da Eduacação. Portaria Interministerial, $\mathrm{n}^{\circ} 1.124$ de 4 de agosto de 2015. Ministério da Saúde. Diário Oficial da União, nº 148 seção 1, 2015, p. 193-6. Institui as diretrizes para a celebração dos Contratos Organizativos de Ação Pública Ensino-Saúde (COAPES), para o fortalecimento da integração entre ensino, serviços e comunidade no âmbito do Sistema Único de Saúde (SUS). Disponível em: URL: http://portalarquivos.saude.gov.br/images/pdf/2015/agosto/05/portaria-inter-1124-2015.pdf. Acessado em 20 de fevereiro de 2016.

\section{Endereço do primeiro autor:}

Emanuelle Tenório de Oliveira

Secretaria Municipal de Saúde de Messias

Rua Elpídio Cavalcante Lins, $s / n^{\circ}$

Bairro: Centro

CEP: 57990-000 - Maceió - AL - Brasil

E-mail: emanuelleoliveira@msn.com

\section{Endereço para correspondência:}

Renato Santos Rodarte

Universidade Federal de Alagoas - UFAL

Instituto de Ciências Biológicas e da Saúde

Avenida Lourival Melo Mota, $s / n^{\circ}$

Bairro: Tabuleiro do Martins

CEP: 57072-900 - Maceió - AL - Brasil

E-mail: rrodarte@icbs.ufal.br 